\title{
A POESIA FEMININA DE EMILY DICKINSON E ADÉLIA PRADO: UMA ESCRITA MEMORIALISTA DO AMBIENTE FAMILIAR
}

\begin{abstract}
MANSOR, Rodrigo ${ }^{1}$
RESUMO: Pretende-se neste artigo analisar a temática da memória, especialmente a feminina, em alguns poemas de Adélia Prado e Emily Dickinson, autoras separadas pelo estilo, o tempo e o espaço, afinal, escreveram poesias com características próprias, vivendo em séculos distintos e em países diferentes. Para isso, traçou-se um panorama histórico da luta da mulher para inserção em espaços públicos e, consequentemente, sua fixação no espaço doméstico/familiar que lhes proporcionou uma escrita memorialística familiar feminina em cartas e poemas que remetem à vida doméstica e às lembranças que acompanham esse espaço privado.
\end{abstract}

PALAVRAS-CHAVE: memória feminina, poesia, Adélia Prado, Emily Dickinson.

\section{THE FEMININE POETRY OF EMILY DICKINSON AND ADÉLIA PRADO: A MEMORIALIST WRITING FROM THE FAMILY ENVIRONMENT}

\begin{abstract}
The intention on this article is to analyze the theme memory specially the female one, in some of Adélia Prado's and Emily Dickinson's poems, authors separated by the style, time and space, hence, they wrote poetry with their own characteristics living in different centuries and in different countries. Therefore, it is traced a historical panoramic of women fight for inclusion in public spaces and, consequently, their remain in the domestic/familiar space, something that has made their memorial and familiar feminine written into letters and poems that remind domestic life and the memories that follow this private scenario.
\end{abstract}

\footnotetext{
${ }^{1}$ Mestrando Programa de Pós-graduação em Letras UFV. Contato: rodrigormansor@ yahoo.com.br Jangada | nr. 15, jan/jun, 2020 | ISSN 2317-4722 
KEYWORDS: feminine memory, poetry, Adélia Prado, Emily Dickinson

\section{INTRODUÇÃO}

A luta contra a desigualdade de gêneros que marca a sociedade contemporânea tem se mostrado um campo fértil para pesquisas sobre os muitos anos em que à mulher couberam as posições subalternas de dona de casa e de guardiã do lar, com imposição de limites invisíveis que a afastou do espaço público. Nos mais diversos campos, porém, sempre surgiram grandes figuras femininas quebrando barreiras, e na esfera das Letras não foi diferente.

Mulheres como Emily Dickinson ${ }^{2}$ e Adélia Prado ${ }^{3}$, hoje nomes de destaque nas literaturas de línguas inglesa e portuguesa, respectivamente, lutaram por brechas no ambiente literário que, embora não seja exclusivamente masculino, é dominado por homens, sejam eles artistas ou críticos. Assim, antes de se enveredarem por espaços que não as comportavam, estas autoras precisaram submeter-se a críticas e conselhos masculinos visando à confirmação de pertencimento ao seleto grupo de escritores.

O estudo do texto ocorreu por meio do entendimento acerca de rimas e paralelismos; de assonâncias e aliterações em $O$ estudo analítico do poema (CANDIDO, 2006), e de unidade do poema em Versos, sons e ritmos (GOLDSTEIN, 2011). A fim de compreender como essas autoras usam a poesia para transmitir memórias, este artigo utilizou-se de publicação de forma condensada da Segunda Conferência proferida por Roman Jakobson (1973) na Faculdade de Letras de Lisboa, intitulada "O que fazem os poetas com as palavras", na qual o mestre aborda questões como repetições, rimas, relação entre som e sentido e paralelismos, além da relação das sociedades com a poesia.

Em De borboletas e colibris em sobrevoo, ao abordar a memória literária Magri (2016) justifica como escritores distintos mantêm traços comuns em seus trabalhos. A essa relação textual, soma-se o empenho feminino para reposicionar a mulher na sociedade, como relata Scott (2011), ao mesmo tempo em que reforça a visão de dominância masculina em praticamente todos os espaços públicos.

Por outro lado, em A história vista de baixo, Sharpe (2011) relata como registros não oficiais tornaram-se fontes genuínas de pesquisa permitindo que vozes antes abafadas pudessem

\footnotetext{
${ }^{2}$ Amherst - Massachusetts (Estados Unidos), 10 de dezembro de 1830 - 15 de maio de 1886.

${ }^{3}$ Divinópolis - Minas Gerais (Brasil), 13 de dezembro de 1935. 


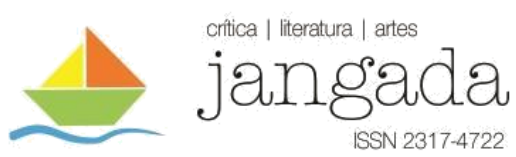

ecoar novas versões de fatos já conhecidos. Analogamente, em A mulher e o espaço público, Perrot (1989) defende que as mulheres limitaram seus discursos e sua escrita ao ambiente restrito ao lar e à família, mas não deixaram de escrever, portanto, não se calaram.

Nesse sentido, Johnson (1965) e Branco (2003) descrevem a solitária voz de Emily Dickinson entre $\operatorname{cartas}^{4}$, bilhetes e poemas ${ }^{5}$ preservando a memória de suas ações e das ações de seus entes queridos, através de detalhes da vida doméstica da mulher americana na metade final do século XIX; na mesma perspectiva, Sant'Anna (2017) e Moriconi (2002) evidenciam a fala humilde e cotidiana de Adélia Prado cujas reminiscências familiares aparecem como seus mais valiosos bens.

Em vista disso, a memória representa, para a mulher, mais do que um repositório de lembranças, um relicário de emoções, uma vez que, como guardiã do lar, em suas reminiscências, é portadora das histórias da família. Destarte, a memória, através do elemento saudosista, transmite a voz de muitas mulheres. Por isso, este artigo visa a analisar a importância da memória para a produção poética de Adélia Prado e de Emily Dickinson, além de investigar a proximidade desse tema em poetas tão díspares quanto elas.

\section{Ser poeta: refúgio na memória como permissão para escrever}

Emily Dickinson e Adélia Prado ecoam a voz e a memória da mulher na literatura mesclando obra e biografia. A fim de criar universos literários coerentes com a realidade a qual estavam intrinsicamente ligadas, batalharam pelo acesso à carreira de escritoras em um meio cujos nomes de destaque, salvo raras exceções, eram masculinos. Tal luta em busca de voz e de emancipação não é exclusiva do meio literário, pois, como afirma Scott (2011, p. 73), "as profissões e as organizações profissionais são estruturadas hierarquicamente: os estilos e padrões dominantes operam para incluir alguns e excluir outros da qualidade de membros".

As mulheres que demandam espaço em sociedades tipicamente patriarcais passam pelo desafio cotidiano de expandir suas conquistas lentamente. Embora Scott (2011) trate de organização profissional, verifica-se uma analogia com o cerceamento do fazer poético por meio de regras ou convenções estipuladas pelo patriarcalismo. Assim, para fazer poesia, Adélia e Emily precisaram passar pelo crivo de um homem. Isso se deve, segundo Scott (2011), a um

\footnotetext{
${ }^{4}$ Todas as traduções de cartas de Emily Dickinson presentes neste artigo foram realizadas por Mourão (2003).

${ }^{5}$ Todas as traduções de poemas utilizadas neste artigo foram realizadas por Lira (In: DICKINSON, 2006). 
legado histórico, pois os homens são os portadores de um saber; portanto, cabe a eles definir quem é capaz de reproduzir esse conhecimento:

A qualidade de membro na profissão histórica confere responsabilidade aos indivíduos que se tornam os guardiães daquele conhecimento que é seu campo de ação especial. A guarda e o domínio são, portanto, a base para a autonomia e para o poder de determinar o que contam como conhecimento e quem o possui. (SCOTT, 2011, p. 73)

Tendo em vista a necessidade de respaldo de um guardião do conhecimento e a fim de encontrar segurança em relação a seus escritos, Emily Dickinson tomou a iniciativa de entrar em contato com Thomas Wentworth Higginson, crítico literário que, segundo Johnson (1965), viria a ser amigo da escritora e um dos seus editores póstumos. Em carta, a norte-americana solicita, com sua forma peculiar de escrever, que o crítico forneça um parecer sobre os versos que ela lhe remetera:

\section{Sr. Higginson,}

O senhor está tão intensamente ocupado para dizer se meu Verso está vivo?

A mente está, ela própria, tão próxima - não pode ver com clareza - e não tenho a quem perguntar -

Se o Sr. achar que respira - e puder me dizer - eu sentiria imediata gratidão Se eu cometo o equívoco - que ousará dizer - e dar-me-á grande honra - com seu gesto -

Incluo aí o meu nome - pedindo-lhe, se me faz o favor - Sr. - de me dizer o que é verdade?

Que o Sr. não me traia - é desnecessário pedir - já que a Honra é sua própria garantia $-^{6}$ (DICKINSON, 2003, p. 71)

A insegurança de Emily Dickinson a fez aproximar-se de um preceptor capaz de validar sua escrita, o que, apesar de não render os frutos esperados, reafirma a necessidade da

\footnotetext{
6 “To T. W. Higginson 15 April 1862

Mr. Higginson,

are you to deeply occupied to say if my Verse is alive?

The Mind is so near itself it cannot see, distinctly - and I have none to ask -

Should you think it breathed - and had you the leisure to tell me, I should feel quick gratitude If I make the mistake - that you dares to tell me - would give me sincerer honor - toward you I enclose my name - asking you, if you please - Sir - to tell me what is true? That you will not betray me - it is needless to ask - since Honor is it's own pawn -"
} 


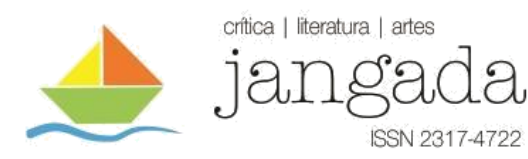

aprovação masculina para que a mulher se sentisse poeta. Algo semelhante ocorreu com Adélia Prado ao enviar seus originais para o escritor e crítico literário Affonso Romano de Sant'Anna. Ela intenta aprovação masculina, e o resultado é mais animador do que o de Dickinson.

A mineira, já uma mulher madura, demonstra agir como uma jovem adolescente na resposta que escreve à carta em que o crítico Sant'Anna a reconhece como poetisa. Adicionando ao texto escrito traços de oralidade típicos da fala daquela mulher do interior de Minas Gerais, Adélia deixa claro que somente após o crivo de seu interlocutor ela pode ouvir que é poeta sem se envergonhar:

[...] Recebi ontem sua carta, melhor, seu presente. Não podia ter me acontecido coisa melhor. Só de noite, com a casa em sossego, dei conta de lêla direito e, então, foi muito engraçado, porque notei um engano (?) seu: 'Se eu pudesse convencer algum editor eu remendaria seus versos...' Eu tava tão 'fominha' que o dia inteiro li remendaria por recomendaria. Dado o todo do contexto da sua carta acho que posso continuar entendendo recomendaria, não é mesmo? Fiquei alegre demais, me deu boca seca, batedeira e riso bobo. Os meninos falavam assim pra mim... 'hoje cê tem que ficar boazinha, mãe. Hoje cê tem que xingar nós não...' Tem pedacinho na carta que eu decorei: aquele de 'liguei pro Drumão'... fala verdade, dá pra qualquer um ficar suspenso. Acho que de agora em diante vou dar conta de ouvir que sou poeta sem ficar vexada. ${ }^{7}$ (PRADO, 2000, p. 17-18)

Nota-se que as poetisas aspiram a um espaço em um meio predominantemente masculino, pois compreendiam que a voz de um homem atestando a qualidade da escrita delas seria mais forte e, provavelmente, não seria contestada no espaço público. Tal como afirma Perrot (1989) ao criticar que às mulheres não cabia o espaço fora das paredes de suas casas, pois os ambientes públicos eram exclusivos dos homens, e apenas estes possuíam o direito de mover a roda da história.

Diante de uma cultura enraizada contra o espaço para mulheres no ambiente público, elas encontraram uma forma de contornar a censura a suas produções literárias atuando como observadoras e historiógrafas de uma realidade mais íntima e restrita: os acontecimentos do lar. Perrot (1989) explica que o fato de as mulheres estarem presas a uma sociedade patriarcal

\footnotetext{
${ }^{7}$ Texto reproduzido de acordo com o original, respeitando a variedade coloquial utilizada pela autora. Jangada | nr. 15, jan/jun, 2020 | ISSN 2317-4722 27 | Pá g in a
} 


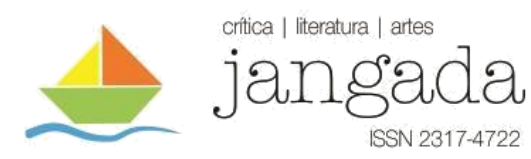

acabou inibindo o envolvimento delas com o mundo exterior, contudo, intensificou a relação de mulheres escritoras limitadas ao mundo onde estavam inseridas.

Partindo da ideia de Perrot (1989), as mulheres são vistas como guardiãs das histórias e dos acontecimentos restritos à família; tornaram-se observadoras atentas do microcosmo no qual se viam inseridas e, em decorrência disso, narradoras dos eventos marcantes de uma história familiar - que viria a se tornar, tempos mais tarde, material relevante para estudar o contexto do período histórico que narram, de acordo com Sharpe (2011).

A produção escrita de diários pessoais, cartas destinadas a amigos e familiares, entre outros gêneros textuais passam, então, a fazer parte de um relicário de informações memoriais sobre hábitos e costumes de uma família ou de um indivíduo. Contudo, Perrot (1989, p. 11-12) alerta para o fato de que o material produzido por mulheres tornara-se sigiloso, já que sua divulgação poderia revelar segredos do lar e arruinar a reputação de uma pessoa ou de toda uma família:

Os arquivos privados, outro sótão da história, fornecem outras informações? Sim, certamente, na medida em que as mulheres neles se exprimiam de forma bem mais abundante, e, até mesmo, foram produtoras desses arquivos, nos casos em que fizeram as vezes de secretárias da família. Livres de raison [Livros de razão] nos quais elas preservam os anais do lar, correspondências familiares cujos escribas habituais são elas, diários íntimos cujo emprego é recomendado às jovens solteiras pelos confessores e, mais tarde, pelos pedagogos, como uma forma de controle sobre si, constituem um refúgio de escritos de mulher, domínio cuja imensidão tudo atesta. Porém esses arquivos sofrem constante destruição e, somente seus escombros - hoje preservados graças ao fato de seu interesse ter sido finalmente reconhecido - nos sugerem sua riqueza. (PERROT, 1989, p. 11-12).

Diante do exposto, é possível afirmar que Perrot (1989) apresenta a mulher como uma entidade privada, reservada, cujos escritos devem ser restritos a temas cotidianos, relacionados à vida familiar e doméstica, como se fossem limitadas a textos cuja única função seria descrever os eventos do dia a dia. Contudo, algumas mulheres como Emily Dickinson e Adélia Prado foram além, enveredando-se em outros gêneros, tais como a poesia, embora tenham mantido, entre outras, a temática da memória familiar. 


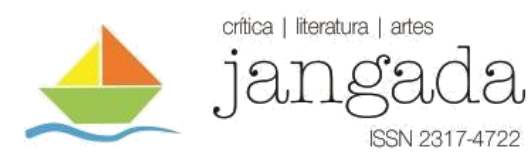

Da mesma forma Scott (2011) defende fortalecimento da noção de identidade feminina, na qual as mulheres requerem domínio em relação a si mesmas e controle sobre a ideia de pertencimento em uma sociedade. Ou seja, ao buscar seu lugar no mundo, visando não ser apagada pela história, a mulher escritora passa a basear seus textos em linhas memorialísticas, pois de tal modo, além de preservar recordações de uma vida particular, extrapola o conceito de privado e insere-se no espaço público da literatura.

Nesse ínterim, a memória feminina, tanto a publicada quanto a atirada à fogueira da censura, é a memória da vida particular, da vida em família, marcada pela intimidade e por fortes laços de convivência que podem vir à tona em pequenos gestos, em um aroma específico, ou mesmo em uma simples fala, que pode ressuscitar lembranças há muito adormecidas, mas que, quando revividas por mulheres saudosistas e mestras na arte de escrever, tornam-se a mais pura literatura memorial.

Emily Dickinson e Adélia Prado inserem-se nessa literatura de memória através de diversos de seus poemas cujos versos apresentam uma fusão entre o eu lírico e suas criadoras, intercalando arte e memória tão naturalmente que o leitor é facilmente envolvido e transportado para as cenas nas quais se desenrolam situações e conflitos familiares corriqueiros tanto para quem escreve quanto para quem lê.

\section{Emily Dickinson e Adélia Prado: cotidiano e família - memórias do feminino}

Nas vezes em que a mulher se ocupa do relato familiar, a literatura feminina inevitavelmente aborda temas da memória. Nestes casos, as rememorações manifestam-se por meio de afazeres domésticos, de uma refeição sendo preparada, ou mesmo da chegada de uma visita, ou seja, situações cotidianas de uma família comum, identificadas com qualquer outra família ao lançar mão de um universo crível, repleto de recordações de um cidadão comum.

Ao tratar da memória literária, Magri (2016) aborda a concepção de intertextualidade explicando como tal conceito ativa gatilhos de memória através do texto ou do contexto. Com isso, o autor permite identificar elementos comuns mesmo em autores cujas obras, ideias, estilos e convicções não se coadunem. Para tanto, o crítico defende a estabilidade do núcleo da memória na literatura entre autores cujas produções não revelam traços marcadamente semelhantes: 


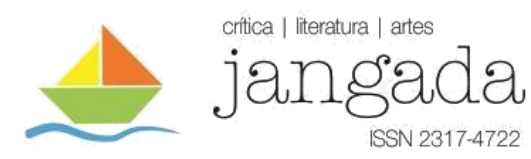

Inserir-se na memória, integrar-se à grande biblioteca, permite o aparecimento de traços comuns em literaturas díspares, instituindo um corpus que se altera ao longo da circulação das ideias. Esse corpus memória submetido à reflexão crítica, à inspiração, às interferências históricas e ideológicas, a preocupações e julgamentos estéticos, é modificado e faz que o memorável apresente zonas de instabilidade, nas quais a importância do texto sofre visível transformação, embora mantenha seu núcleo estável. (MAGRI, 2016, p. 97)

Adélia Prado e Emily Dickinson apresentam aspectos comuns na escolha de algumas de suas temáticas, entre elas a religiosidade, o contato com a natureza, a simplicidade da vida, a relação entre a mulher e família, e o confronto entre mulher e sociedade, conforme destacam seus respectivos biógrafos, Sant'Anna (2017) e Johnson (1965). Tais aspectos enquadram-se no que Magri (2016) define como "núcleo estável” da memória.

Entretanto, o mesmo autor defende a existência de "zonas de instabilidade" capazes de acarretar modificações claras na importância do texto, como ocorre, por exemplo, no relacionamento que essas duas poetisas mantêm com Deus: enquanto a americana mostra-se íntima (JOHNSON, 1965), a brasileira usa tom cerimonioso para comunicar-se com o divino (SANT'ANNA, 2017). A mesma inconsistência ocorre quando tratam de relacionamentos amorosos: Dickinson é velada e resguardada (JOHNSON, 1965); Prado, em alguns poemas, é erótica e mundana (SANT'ANNA, 2017).

Desse modo, apesar da clara diferença de estilos, há de se ressaltar que imposições temporais e de estilo relativas aos costumes e à moral de cada época podem ser responsáveis pelo distanciamento de abordagem das autoras aqui estudadas. Contudo, elas são unidas pela presença da temática da memória, que se dá através de uma escrita feminina, seja ela da mulher reservada, que se isola do mundo, ou da mulher contestadora que quer se libertar de imposições retrógradas da sociedade.

Nesse viés, Emily Dickinson possui grande parte de sua biografia envolta em mistério, o que rende um número considerável de lendas acerca da vida e da obra da "Bela de Amherst". Dentre os elementos inquestionáveis de sua biografia, sabe-se que a poetisa nasceu, viveu e faleceu na pequena cidade de Amherst, Massachusetts, no berço de uma família relativamente importante, cujo patriarca exercia forte influência na comunidade local.

Ter nascido em família tradicionalmente puritana fez Emily Dickinson frequentar em sua juventude um colégio para moças, o Mount Holyoke Female Seminary, onde adquiriu Jangada | nr. 15, jan/jun, 2020 | ISSN 2317-4722 


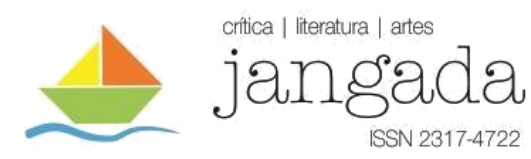

bastante conhecimento acerca de Bíblia e da religião cristã, as quais exercem forte influência sobre sua obra. De acordo com Johnson (1965),

a pessoa que Emily Dickinson se tornou e a poesia que ela escreveu só podem ser compreendidas dentro das estruturas das tradições do vale, que ela herdou, e da família em que nasceu. Ao tempo em que Hawthorne fixava o iniludível passado puritano, ela o exemplificava através do tranquilo drama da sua vida. (JOHNSON, 1965, p. 20)

Contudo, a autora logo renunciou à religião, expressando sua religiosidade e sua espiritualidade sem os grilhões impostos pela Igreja ou pelos religiosos envolvidos com ela, entre eles seu próprio pai. Então, a partir desse momento, ela começa a mostrar-se mais solitária e reclusa, oferecendo material para compor o imaginário que se criou ao seu redor, e que permeou toda sua obra e, por conseguinte, os estudos acerca desta.

Branco (2003) destaca como Dickinson evitava o contato direto com outras pessoas, a ponto de esconder-se em seu quarto, e revela uma nova tradição na vida da autora: sua ideia fixa de vestir-se apenas com roupas brancas. Tal isolamento afastou Emily Dickinson do convívio em sociedade: não saía de casa, nem conversava pessoalmente com ninguém fora de seu restrito círculo de amigos. Branco (2003) descreve esse desejo de isolamento cujos resultados reforçam o imaginário resultante dos costumes da poetisa:

Desde a idade dos 28 anos, deixou-se tomar pela mania de correr quando a campainha toca. No ano seguinte, inauguraria o hábito de se vestir exclusivamente de branco, hábito que manteria pelo resto de sua vida. Nas raras ocasiões em que consentia a visita de velhos amigos, ela e o visitante conversariam através da porta semicerrada. (BRANCO, 2003, p. 20)

Toda essa excentricidade resultou numa mulher isolada, contudo, possuidora de um olhar diferenciado sobre o mundo. Olhar esse expresso através de suas poesias e de suas cartas: escritas que representavam o principal passatempo de uma mulher em sua época, além de acesso mais comum de uma mulher com a produção escrita. Assim, sua correspondência representou uma das formas que Emily Dickinson usou para preservar a sua memória, a memória de seu tempo e a sua relação com o mundo: 
Eis minha carta ao Mundo

Que nunca me escreveu -

Breves Notícias que com Fidalguia

A Natureza deu

Trazem Sua Mensagem

Mãos que não posso ver -

Por Ela me julgueis - gentis Senhores -

Com brando parecer

(DICKINSON, 2006, p. 97)

Em versos, Emily Dickinson exalta um de seus hábitos mais queridos: o de escrever cartas (letters). De acordo com Johnson (1965), essa atividade era tão comum para a escritora que as missivas enviadas aos seus amigos e familiares compõem hoje grande percentual do material com vistas a compreender sua obra. A poetisa fazia de suas epístolas uma maneira de praticar a escrita ao mesmo tempo em que mantinha contato com o mundo fora da bolha em que se isolou, contribuindo dessa forma com a escrita memorialística feminina.

A autora mescla a natureza, tema marcante como refúgio da realidade em sua obra, com as questões ligadas aos seus hábitos saudosistas. Para apelar por um julgamento brando a seus iguais (countrymen) ela utiliza-se do paralelismo, com função conativa, como defende Jakobson (1973, p. 8), marcando-o na "repetição de sons" (World/told; Me/Majesty/see - nas rimas; e nos fonemas linguodentais iniciados por /t/), "a repetição de categorias gramaticais" (told/commited/see - verbos).

A escrita de cartas, poesias e pequenos bilhetes, também enviados a pessoas próximas, reforça a necessidade feminina de garantir a manutenção da memória ligada à vida familiar e ao mundo fechado no espaço privado que a autora tanto prezava. Esse apego ao isolamento garantiu a Emily uma escrita cuja memória confunde-se com uma casa, isso quando as lembranças não são a própria casa, como é visto em uma de suas poesias:

Tem Frente e Fundos a Memória -

Como uma Casa tem -

Para o Despejo e para o Rato

Há um sótão também.

\footnotetext{
${ }^{8}$ This is my letter to the World/That never wrote to Me -/ The simple News that Nature told - / With tender Majesty// Her Message is committed/ To Hands I cannot see -/ For love of Her - Sweet - countrymen -/ Judge tenderly - of Me

Jangada | nr. 15, jan/jun, 2020 | ISSN 2317-4722 
E ainda a Adega mais profunda

Que um Pedreiro já fez -

Ao descer lá toma Cuidado

Ou pegam-te de vez. ${ }^{9}$

(DICKINSON, 2006, p. 117)

Nesse poema, Dickinson (2006, p. 116) cria um jogo com a rima House/Mouse (Casa/Rato), destacando as iniciais com maiúsculas - a fim de relacionar os hábitos do lar a um ser insignificante, contudo, preso naquele momento de sua lembrança. Por mais que a rima soe grotesca, a inserção desse ser cativo na casa auxilia na criação da imagem da memória como um lar, pois, de acordo com Jakobson $(1973$, p. 6) "a questão fundamental reside, em poesia, nas relações entre som e sentido. Age a cada momento, estabelecendo entre as palavras novos nexos, metafóricos ou metonímicos."

Em outras palavras, Jakobson (1973) afirma que o poeta deve associar as palavras tanto pela sonoridade quanto pelo sentido, atribuindo àquele contexto um novo entendimento de relações, como o criado pela poetisa norte-americana ao relacionar a memória de casa, até mesmo, ao detalhe mais insignificante, ou indesejado, capaz de irromper lembranças que perseguem quem vai ao sótão - local onde são guardadas as memórias mais escondidas.

Dickinson funde em sua poesia lar e memória. Demonstra transitar por ambos os espaços ao mesmo tempo sem ser incoerente, uma vez que acredita viver no refúgio de seu lar, porém, tem certeza de que está presa, ou assombrada, por memórias que vagueiam pelos mesmos cômodos que ela. Exatamente por isso, em outros versos, Dickinson (2006, p. 102) alerta que "a memória é um sino original -/ Festa e funeral"10, dando indícios de que não é bom ficar preso às memórias.

Em consonância com a obra de Dickinson e com a produção de memória feminina defendida por Perrot (1989) encontram-se versos da obra de Adélia Prado que ecoam a voz da mulher entregue de corpo e alma para a vida doméstica, sem deixar de cultivar na poesia as reminiscências típicas de quem vê na família seu motivo de vida.

Adélia Prado ganhou espaço na literatura brasileira através do incentivo de dois nomes consagrados em nossa literatura: Affonso Romano de Sant'Anna, crítico literário que primeiro teve contato com os manuscritos de Bagagem (obra inaugural da poetisa mineira); e Carlos

\footnotetext{
${ }^{9}$ Remembrance has a Rear and Front -/ 'Tis something like a House -/It has a Garret also/ For Refuse and the Mouse.// Besides the deepest Cellar/That even Mason laid -/Look to it by its Fathoms/Ourselves be not pursued

${ }^{10}$ Memory is a strange bell -/Jubilee and knell.
}

Jangada | nr. 15, jan/jun, 2020 | ISSN 2317-4722 


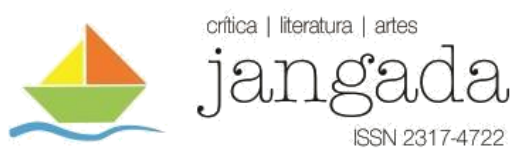

Drummond de Andrade, um dos maiores poetas da literatura brasileira, que recebeu das mãos de Sant'Anna os manuscritos de Adélia e prontamente recomendou sua publicação por considerar seus poemas "fenomenais".

Nascida no interior de Minas Gerais, Adélia Prado levou a literatura como objeto à margem de sua vida interiorana até os quarenta anos, quando publicou sua primeira coletânea poética. Desde então, é nome de destaque na cena literária nacional, tendo lançado cerca de dez livros de poesia, sem contar outros tantos em prosa, mesmo que ainda seja recordada por críticos como uma dona de casa que escreve. Sant'Anna (2017, p. 485) toma como natural esta prática de Adélia "que já se definia como 'mulher do povo', que faz a própria comida, que aos domingos bate o osso no prato pra chamar o cachorro e atira restos, constitui um "caso" em nossa poesia”. A referência de Sant'Anna à simplicidade de Adélia vem da própria autora no poema "Grande desejo":

Não sou matrona, mãe dos Gracos, Cornélia, sou é mulher do povo, mãe de filhos, Adélia.

Faço comida e como.

Aos domingos bato o osso no prato para chamar o cachorro e atiro os restos.

Quando dói, grito ai, quando é bom, fico bruta, as sensibilidades sem governo. Mas tenho meus prantos, claridades atrás do meu estômago humilde e fortíssima voz para cânticos de festa.

Quando escrever o livro com o meu nome e o nome que vou pôr nele, vou com ele a uma igreja, a uma lápide, a um descampado, para chorar, chorar, e chorar, requintada e esquisita como uma dama.

(PRADO, 2017, p. 17-18)

Sant'Anna (2017) utiliza-se do poema “Grande desejo" para afirmar que, apesar de ser uma escritora publicada e elogiada pela crítica, Adélia ainda é a pessoa simples que realiza os afazeres domésticos e, nesses afazeres, resvala a alma humana com domínio e sensibilidade de filósofa. No prefácio que escreveu para o segundo livro da autora, o crítico e poeta continua o elogio à conterrânea, para Sant'Anna (2017, p. 486) “na verdade, trata-se da voz mais feminina de nossa poesia até hoje. Adélia não usa uma linguagem de empréstimo aos homens, nem repete pieguices em torno de imagens de noite-lua-canto-rosa-mar-estrela-solidão”.
Jangada | nr. 15, jan/jun, 2020 | ISSN 2317-4722
34 | P á g in a 
A feminilidade apontada pelo crítico acaba por se tornar uma característica da obra da poeta mineira, juntamente com outros temas recorrentes, tais como a memória, o cotidiano, a sexualidade e a religiosidade. Uma marca que a própria Prado (2017, p. 43) expressa em versos desde sua primeira publicação:

\section{Endecha das três irmãs}

As três irmãs conversavam em binário lentíssimo.

A mais nova disse: tenho um abafamento aqui, e pôs a mão no peito.

A do meio disse: sei fazer umas rosquinhas.

A mais velha disse: faço quarenta anos, já.

A mais nova tem a moda de ir chorar no quintal.

A do meio está grávida.

A mais cruel se enterneceu por plantas.

Nosso pai morreu, diz a primeira,

nossa mãe morreu, diz a segunda,

somos três órfãs, diz a terceira.

Vou recolher a roupa no quintal, fala a primeira.

Será que chove?, fala a segunda.

Já vieram as minhas sempre-vivas?, falou a terceira, a de coração duro, e soluçou.

Quando a chuva caiu ninguém ouviu os três choros dentro da casa fechada.

(PRADO, 2017, p. 43)

Adélia Prado escolhe os assuntos mais triviais do dia a dia para produzir poesia. Em Endecha das três irmãs, o eu lírico apresenta a vida de três mulheres adultas através de um diálogo trivial marcado pela repetição. Tal estratégia é usada com frequência por Adélia Prado para tratar da memória. São lembranças familiares; conversas sobre o passado, sobre um tempo que não volta, mas que ressurge em reminiscências da escritora mineira.

A sonoridade produzida pelo chiado dos fonemas do penúltimo verso (chove/choros) reforça a tristeza provocada pelo saudosismo que abala as três irmãs em seu canto lamurioso. Para Candido (2006, p. 50) isso ocorre, pois "todo verso tem assonâncias e aliterações que constituem a base da sua sonoridade, e que contribuem poderosamente para o seu efeito". A isso se soma a repetição tida por Jakobson (1973) como intencional para efeitos poéticos:

Projecta-se na linguagem poética o princípio da equivalência na sequência; as

sílabas, os acentos tornam-se unidades equivalentes. No verso livre, não são 


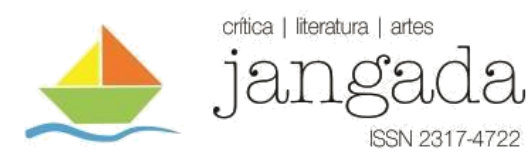

os acentos, não são as sílabas, mas é a entonação da frase que se repete, formando por essa reiteração regular a própria base do verso. (JAKOBSON, 1973, p. 6)

Jakobson (1973) explica que a repetição quando ocorre em prosa não demonstra real valor, contudo, em versos, o estudioso exalta a repetição intencional, e pode ocorrer tal como em Endecha das três irmãs de forma explícita (versos 9 a 14, onde a autora expõe um verbo elocutivo e alterna a fala das irmãs) ou implícita (versos 1 a 8 , em que as irmãs repetem suas lamúrias).

A forma como Adélia Prado descreve cenas, situações e personagens em suas poesias indica que há mais do que eu lírico em sua escrita, há também a voz da Adélia, mulher, filha, irmã. Ao repetir frases ou situações, como se estivesse rezando uma ladainha religiosa, o que ela faz é misturar realidade e ficção, fornecendo aos seus versos motivos vívidos e vividos por ela. Assim, a autora vale-se da repetição de trechos de versos para reafirmar a ideia de perda que não deve ser esquecida.

Para Moriconi (2002, p. 141) Adélia Prado “inaugurou o 'politicamente correto’ na poesia brasileira, substituindo o gesto poético da máscara, da persona, pelo gesto poético de uma autenticidade autobiográfica corroborada pelo corpo". Diante da estratégia comum em Adélia Prado de mesclar vida e obra, eu lírico e poeta, as narrativas de memórias familiares, nas quais destaca a visão da mulher interiorana e dona de casa, tornam-se ainda mais perceptíveis. Dessa vivência, Prado (2017) produz poemas com teor memorialístico e biográfico, como em "As mortes sucessivas":

Quando minha irmã morreu eu chorei muito e me consolei depressa. Tinha um vestido novo e moitas no quintal onde eu ia existir.

Quando minha mãe morreu, me consolei mais lento, tinha uma perturbação recém-achada: meus seios conformavam dois montículos e eu fiquei muito nua, cruzando os braços sobre eles é que eu chorava. Quando meu pai morreu, nunca mais me consolei. Busquei retratos antigos, procurei conhecidos, parentes, que me lembrassem sua fala, seu modo de apertar os lábios e ter certeza. Reproduzi o encolhido do seu corpo 
em seu último sono e repeti as palavras

que ele disse quando toquei seus pés:

'deixa, tá bom assim'.

Quem me consolará desta lembrança?

Meus seios se cumpriram

e as moitas onde existo

são pura sarça ardente de memória.

(PRADO, 2017, p. 95)

Nos versos de "As mortes sucessivas", o eu lírico chora a morte de parentes próximos, principalmente a do pai, e sai à procura de objetos de recordação, ao mesmo tempo em que sofre mudanças naturais no corpo e na mente. Sabe que a vida segue apesar das perdas, mas não perde tempo fraquejando, pois, como mulher, deve manter a história da família viva e, para isso, busca no mundo externo e em objetos do passado recriar o pai falecido.

Além das informações explícitas pelo eu lírico, há um aspecto visual que reforça a ideia de perda, que pode ser compreendida com o isolamento de grupos de versos, o que segundo Goldstein (2011, p. 11) é aceitável, pois “ao analisar um poema, é possível isolar alguns de seus aspectos, em um procedimento didático, artificial e provisório". Se os versos forem lidos por seu conteúdo, isolando cada uma das perdas, percebemos um processo de gradação: a morte da irmã ocupa três versos (é menos sofrida); a da mãe ocupa cinco (mais difícil de consolar); por fim, a do pai ocupa onze versos (não foi superada).

O eu lírico, apesar de sensibilizar-se de forma diferente para as perdas, preserva a memória de todos, assim como Adélia preservou a memória de sua família em suas lembranças e em seus versos, porém, ela levanta um questionamento que desmistifica essa figura de guardiã da memória familiar: quem será capaz de consolar a mulher depois de perdas tão profundas? Quem teria força suficiente para preservar tantas dores sem um apoio? Quem há de estar ao lado da mulher quando a memória, sem aviso prévio, vier à tona?

\section{CONSIDERAÇÕES FINAIS}

A área da literatura, desde sempre, relaciona-se intensamente com as percepções da memória. Sabendo-se disso, torna-se viável estudar a literatura escrita por mulheres a fim de compreender como a memória funciona para autores e leitores. Dessa forma, reminiscências de um escritor produzem percepções de semelhança nos leitores que, de modo catártico, podem sentir-se pertencentes ao universo literário no qual estão imergindo. 


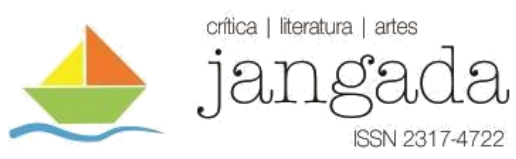

Quando a memória em questão aborda a vivência feminina, a sensação de pertencimento torna-se ainda maior, até mesmo para homens, pois se entende que a mulher possui a guarda da memória da família, do cotidiano e da vida particular, além de dispor do direito de relatá-los, como defendido por Perrot (1989), logo, seus escritos provocam reminiscências que evocam situações nostálgicas a quem quer que os leia.

Percebe-se, contudo, que para assumir o lugar de cronista da memória familiar, a mulher percorreu um caminho repleto de percalços que a acompanham desde tempos remotos. A inferiorização da mulher perante o homem, por exemplo, apesar de já ter diminuído minimamente, é um fato histórico cuja modificação parece distante. Contudo, podemos perceber manifestações em diversos campos de atividade humana, como o da literatura, com o intuito de reduzir a relação de dominância entre os gêneros.

As pesquisas envolvendo pessoas consideradas subalternas, ou seja, aquelas a quem foi relegado menor interesse social, configuram um fenômeno recente no campo literário. Dessa forma, as mulheres, que representam parte considerável desse grupo, precisaram desbravar caminhos incertos para inscreverem seus nomes nos cânones. Em suma, o paradigma de submissão e subalternidade é rompido somente quando elas ousam desafiar os padrões impostos pelos grupos dominantes.

Apesar de escreverem poemas e não narrativas em prosa, Adélia Prado e Emily Dickinson contribuem com a tradição de mulheres cujos relatos pessoais remetem à memória familiar, à memória do lar. Dessa forma, apresentam a mulher que acata o modelo de escrita que lhe fora imposto, mas movimenta-se em outras direções, indicando uma tentativa de ampliar seus espaços.

Por fim, a literatura memorial demonstra-se bastante receptiva à criação literária feminina, contudo, ainda é necessário entender se as escritoras enquadram-se nessa tradição por afinidade ou por imposição velada dos costumes que lhes restringe o espaço público. Assim, cabe à mulher poeta optar ou não por ser cronista do lar e guardiã de memórias da família, pois se ela domina a memória da família em seus detalhes, ela também insere a família e a si mesma em uma sociedade, o que lhe possibilita escrever além das fronteiras da memória familiar.

\section{REFERÊNCIAS BIBLIOGRÁFICAS}

BRANCO, Lúcia Castello. A branca dor da escrita: três tempos com Emily Dickinson. Belo Horizonte: 7Letras, 2003.

Jangada | nr. 15, jan/jun, 2020 | ISSN 2317-4722

38 | Pá g in a 


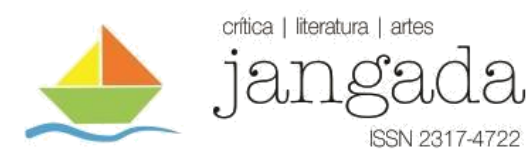

CANDIDO, Antônio. O estudo analítico do poema. 5. ed. São Paulo: Associação Editorial Humanitas, 2006.

DICKINSON, Emily. Alguns Poemas. Trad. José Lira. São Paulo: Iluminuras, 2006. . Cartas. In.: BRANCO, Lucia Castello. A branca dor da escrita: três tempos com Emily Dickinson. Belo Horizonte: 7Letras, 2003.

GOLDSTEIN, Norma. Versos, sons e ritmos. 14. ed. São Paulo: Ática, 2006.

JAKOBSON, Roman. O que fazem os poetas com as palavras. In: Revista Colóquio/Letras, $\mathrm{n}^{\circ}$ 12, Mar., 1973, p. 5-9.

JOHNSON, Thomas H. Mistério e Solidão: a vida e a obra de Emily Dickinson. Trad. Vera das Neves Pedroso. Rio de Janeiro: Lidador, 1965.

MAGRI, Dirceu. De borboletas e colibris em sobrevoo: presença francesa nas crônicas machadianas. São Paulo: FAP/Unifesp, 2016.

MORICONI, Ítalo. Como e por que ler a poesia brasileira do século XX. Rio de Janeiro: Objetiva, 2002.

MOURÃO, Fernanda. Cartas. In: BRANCO, Lucia Castello. A branca dor da escrita: três tempos com Emily Dickinson. Belo Horizonte: 7Letras, 2003.

PERROT, Michelle. Práticas da memória feminina. In: BRESCIANI, Maria Stella Martins. Revista Brasileira de História. Trad. Cláudio Henrique de Moraes Batalha e Miriam Pillar Grossi. São Paulo: ANPUH/Marco Zero, 1989.

PRADO, Adélia. Poesia reunida. Rio de Janeiro: Record, 2017.

- [Carta]. Destinatário: Affonso Romano de Sant'Anna. In: FRANCESCHI, Antonio

Fernando de. Cadernos de literatura brasileira: Adélia Prado. São Paulo: Instituto Moreira Salles, 2000.

SANT'ANNA, Affonso Romano de. Prefácio. In: PRADO, Adélia. Poesia reunida. Rio de Janeiro: Record, 2017.

SCOTT, Joan. História das mulheres. In: BURKE, Peter, A escrita da história: novas perspectivas. Trad. Magda Lopes. São Paulo: UNESP, 2011.

SHARPE, Jim. A história vista de baixo. In: BURKE, Peter. A escrita da história: novas perspectivas. Trad. Magda Lopes. São Paulo: UNESP, 2011. 